\title{
O FENÔMENO DA "FILA DUPLA" OU "SEGUNDA PORTA" NO Sistema Único de SaÚde E A INOBSERvânCIA AO PRINCÍPIO dA IMPESSOALIDADE: UM EXERCÍCIO DE APROXIMAÇÃO DE CONCEITOS
}

\author{
THE "DOUBLE LINE" OR "SECOND DOOR" PHENOMENON \\ IN THE BRAZILIAN NATIONAL HEALTH SYSTEM (SUS) AND THE \\ INOBSERVANCE OF THE IMPERSONALITY PRINCIPLE: \\ APPROACHING CONCEPTS
}

Mariana Faria Teixeira ${ }^{(*)}$
Roberto Gomes Patrício $^{(* *)}$

\section{RESUMO}

Cumpre salientar ab initio que, para elaboração do presente artigo, em face da interdisciplinaridade exigida pelo tema escolhido, foi necessária incursão na área da Ciência Jurídica, bem como, na área da Saúde Coletiva para uma compreensão contextualizada do tema trabalhado. O objetivo deste artigo é realizar o levantamento bibliográfico de obras sobre Direito Administrativo e seus princípios, Direito Sanitário, acesso ao Sistema Único de Saúde e os fenômenos da "fila dupla" da "segunda porta" no SUS a fim de analisar a relação entre a inobservância do Princípio da Impessoalidade e a geração dessas iniquidades no acesso aos Serviços de Saúde do SUS. O referencial teórico se baseia tanto em autores que definem os princípios do Direito Administrativo, o conceito de acesso e ainda naqueles que denunciam as iniquidades no SUS, especialmente o fenômeno da "segunda porta" ou "fila dupla".

(*) Advogada, especialista em Direito Sanitário pela Escola Nacional de Saúde Pública (ENSP) e Mestranda em Saúde Pública pela Escola Nacional de Saúde Pública (ENSP); secretária-executiva do Centro Brasileiro de Estudos de Saúde (CEBES). Rio de Janeiro/RJ-Brasil. E-mail: $<$ marianafaria250@ hotmail.com>.

$\left.{ }^{(*}\right)$ Graduado em Direito pela Universidade Estácio de Sá, administrador do Centro Hospitalar do Instituto de Pesquisa Clínica Evandro Chagas (IPEC) da Fundação Oswaldo Cruz (FIOCRUZ). Rio de Janeiro/RJ-Brasil. E-mail:<roberto.patrício @ipec.fiocruz.br>. Recebido em 02.07.09. Revisado em 03.05.10. Aprovado em 04.08.10. 


\section{Palavras-chave}

Acesso ao Sistema de Saúde; Administração Pública.

\section{ABSTRACT}

The present article was written in an interdisciplinary field, uniting the Collective Health and the Law areas of study. The purpose of the article was to do a bibliographic review of Administrative Law, Health Law, Collective Health and Iniquities in SUS works. This paper's conceptual basis resides mainly in authors that define the Administrative Law principles, the access concept and also in the ones who denounce the iniquities in SUS, specially the "second door" or "double line" phenomenon.

\section{Keywords}

Access to Health System; Public Administration.

\section{INTRODUÇÃO}

Para compreender a relação de causalidade entre a inobservância por parte do profissional e/ou gestor (agentes públicos da área da saúde) do Sistema Único de Saúde (SUS) do Princípio da Impessoalidade e a geração de iniquidades no acesso do usuário aos serviços de saúde, especialmente do fenômeno da "fila dupla" ou "segunda porta", este artigo foi dividido em sete partes - divisão considerada necessária, pois trataremos de aproximar duas áreas do conhecimento científico: a jurídica e a da saúde coletiva, as quais possuem sua própria linguagem, doutrinadores e princípios.

Portanto, com o objetivo de falar para ambas as áreas e seu público, fez-se necessário caracterizar, inicialmente, o que estamos tratando como Direito Sanitário, visto que este é um campo multidisciplinar, com diversas delimitações conceituais e teóricas. Isto posto, seguimos aproximando as áreas do conhecimento, situando o SUS enquanto administração pública e o usuário enquanto administrado, a fim de que pudéssemos, mais adiante, tratar do princípio da impessoalidade, que se encontra dentro do campo de conhecimento jurídico, sem atropelos àqueles da área da saúde. Preocupamo-nos em conceituar "acesso", delimitando ao que nos referiríamos ao falar das iniquidades.

Por fim, elucidamos o fenômeno da "fila dupla" ou "segunda porta" e buscamos indicar a relação entre essas e outras iniquidades com a falta 
de cumprimento do Princípio da Impessoalidade, apontando, ao final, os meios legais que o usuário/administrado possui para buscar o acesso universal e igualitário, garantido pela Constituição.

\section{A POSITIVAÇÃO DO DIREITO À SAÚDE E O CONCEITO DE DIREITO SANITÁRIO}

A garantia de acesso a serviços integrais de saúde surgiu no final da Segunda Guerra Mundial no Reino Unido, com a criação do National Health Service (NHS). A lei de criação do NHS, em 1946, estabeleceu o princípio da responsabilidade coletiva por serviços completos (comprehensive health services) que deveriam ser disponibilizados de forma gratuita a toda população.

No Brasil, o Direito à Saúde emerge no constitucionalismo contemporâneo dentro da categoria dos chamados "direitos sociais"(1). A Constituição de 1988 incorpora claramente esse caráter do direito à saúde quando, no art. 196, estabelece que ele será "garantido mediante políticas sociais e econômicas que visem à redução do risco de doenças e de outros agravos e ao acesso universal igualitário às ações e serviços para sua promoção, proteção e recuperação". Além disso, outros dispositivos da Constituição também impõem obrigações ao Estado nesse campo, como o art. 23, II, que estabelece como competência comum dos entes federativos "cuidar da saúde", e o art. 24, XII, que inclui no âmbito da competência concorrente a legislação sobre "proteção e defesa da saúde".

Portanto, o direito à saúde foi constitucionalizado em 1988 como direito público sujeito a prestações estatais, ao qual corresponde o dever dos Poderes Públicos desenvolverem as políticas que venham garantir esse direito.

Assumindo o Estado a concretização do direito à saúde como prestação de um serviço público, faz-se necessário a produção de grande quantidade de textos legais a fim de reger a execução desse serviço. O Direito Sanitário é o conjunto desses textos legais. Ou como melhor nos explica Aith(2) "O Direito Sanitário é um conjunto sistematizado de normas jurídicas, regras e princípios”.

Seguindo nessa lógica, já que o Direito Sanitário tem como interesse o exercício do direito à saúde coletiva, temos nas palavras de Dallari(3):

(1) BOBBIO, Norberto. A era dos direitos. Rio de Janeiro: Campus, 1992.

(2) AITH, Fernando M. A. Curso de direito sanitário. São Paulo: Quartier Latin, 2007. p. 120.

(3) DALLARI, Sueli Gandolfi. Direito sanitário. In: ARANHA, Márcio lorio; TOJAL, Sebastião Botto de Barros (Orgs.). Curso de Especialização a distância em Direito Sanitário para Membros do Ministério Público e da Magistratura Federal - Programa de Apoio ao Fortalecimento do Controle Social no SUS. Brasília: UnB, 2002. p. 49. 
O direito da saúde pública é, portanto, parte do que tradicionalmente se convencionou chamar de direito administrativo, ou uma aplicação especializada do direito administrativo. É parte do direito administrativo porque refere sempre atuações estatais orientadas, o mais exaustivamente possível, pela própria sociedade, por meio do aparelho legislativo do Estado.

Ainda no mesmo sentido, segundo Alessi (apud Moraes, 2001), o Direito Sanitário é aquela parte do direito administrativo que disciplina o exercício da função sanitária dos entes públicos, ou melhor, a função pública direta da tutela e a realização do interesse sanitário da coletividade.

Pelo exposto, podemos compreender que o Direito Sanitário deve ser entendido como uma ramificação do Direito Administrativo, pois foi buscar nele o embasamento doutrinário necessário à construção do arcabouço jurídico que consubstancia as normas de direito positivo, as quais estabelecem direitos e deveres e regulam atividades públicas em matéria de saúde, indicando as sanções aplicáveis aos infratores. Dessa forma, entendemos, por analogia, que o Direito Sanitário está submetido diretamente aos mesmos princípios que vigem o Direito Administrativo.

\section{O SUS COMO ADMINISTRAÇÃO PÚBLICA}

Compreendendo a delimitação de Direito Sanitário que utilizaremos no decorrer deste texto, passaremos a analisar, preliminarmente, alguns conceitos que julgamos fundamentais para compreensão da relação entre a inobservância do Princípio da Impessoalidade e a geração do fenômeno da "fila dupla" ou "segunda porta", fenômeno de iniquidade de acesso ao SUS. Ao mesmo tempo, nos ocuparemos em aproximar conceitos, verbetes e linguagens, reforçando a necessidade desta aproximação, visto tratar-se de área de conhecimento interdisciplinar.

A legitimação do direito à saúde na sociedade contemporânea se envolve numa relação dialética entre o Estado e seus administrados. A fim de compreender essa relação dialética, faz-se mister conhecer seus sujeitos.

$\mathrm{O}$ conceito de administrados, neste caso, se refere aos usuários de saúde/pacientes e suas respectivas famílias.

O Estado pode ser entendido como sendo pessoa jurídica soberana que realiza os seus objetivos por meio da administração pública. E o que se entende por Administração Pública? Segundo nos ensina Maria Sylvia Zanella Di Pietro ${ }^{(4)}$ o conceito de administração pública divide-se em dois sentidos: "Em sentido objetivo, material ou funcional, a administração pública pode ser

(4) DI PIETRO, Maria Sylvia Zanella. Direito administrativo. 6. ed. São Paulo: Atlas, 2003. p. 61-62. 
definida como a atividade concreta e imediata que o Estado desenvolve, sob regime jurídico de direito público, para a consecução dos interesses coletivos. Em sentido subjetivo, formal ou orgânico, pode-se definir Administração Pública, como sendo o conjunto de órgãos e de pessoas jurídicas aos quais a lei atribui o exercício da função administrativa do Estado."

Assim, administração pública em sentido material é administrar os interesses da coletividade e em sentido formal é o conjunto de entidades, órgãos e agentes que executam a função administrativa do Estado.

Nesse sentido, o Sistema Único de Saúde (SUS), suas ações e profissionais devem ser considerados administração pública, tanto em sentido formal quanto material.

Em consonância com esta afirmação, Santos ${ }^{(5)}$ expressa que o Sistema Único de Saúde é um setor da Administração Púbica.

\section{CONCEITO DE ACESSO AOS SERVIÇOS DE SAÚDE}

"Acesso" é um conceito complexo, muitas vezes empregado de forma imprecisa, e pouco claro na sua relação com o uso de serviços de saúde. A fim de podermos compreender as iniquidades que são geradas pela administração pública, nos serviços de saúde, será imprescindível que delimitemos de qual conceito de acesso estaremos falando.

Em seu artigo, "Uma revisão sobre os conceitos de acesso e utilização de serviços de saúde", Travassos \& Martins ${ }^{(6)}$ nos trazem diferentes conceitos de Acesso que perpassam por diferenças de nomenclaturas como acessibilidade ou acesso, variedades de abrangência e por distintos autores que se dedicaram a estudar o acesso aos serviços de saúde como Donabedian, Andersen, Penchansky \& Thomas Starfield, Goddard \& Smith e Frenk. Entre os debates apontados, se destaca a dificuldade que os conceitos adotados pela Organização Mundial de Saúde (OMS) e pelo Instituto de Medicina dos Estados Unidos (IOM) têm em diferenciar, por exemplo, "o uso da qualidade" do cuidado.

O Comitê para o Monitoramento do Acesso aos Serviços de Saúde do Institute of Medicine (IOM) dos Estados Unidos propõe que acesso seja definido como o "uso de serviços de saúde em tempo adequado para obtenção do

(5) SANTOS, Lenir. Saúde: conceito e atribuições do Sistema Único de Saúde. Jus Navigandi, Teresina, ano 9, n. 821, 2 out. 2005. Disponível em: <http://jus2.uol.com.br/doutrina/texto.asp?id=7378>. Acesso em: 02 maio 2010.

(6) TRAVASSOS, Claudia; MARTINS, Mônica. Uma revisão sobre os conceitos de acesso e utilização de serviços de saúde. Caderno de Saúde Pública, Rio de Janeiro, v. 20, supl. 2, 2004. Disponível em: $<$ http://www.scielosp.org/scielo.php?script=sci_arttext\&pid=S0102-311X2004000800014\&lng= pt\&nrm=iso>. Acesso em: 15 fev. 2009. 
melhor resultado possível". Já a OMS sugere um novo indicador, que chama de "cobertura efetiva". "Cobertura efetiva foi definida como a proporção da população que necessita de um determinado procedimento de saúde e que recebeu de forma efetiva este procedimento".

Apesar de reconhecermos a importância da discussão levantada no supracitado artigo, para o desenvolvimento deste debate, nos bastará considerar o conceito de acesso como indicador do grau de facilidade com que as pessoas obtêm cuidados de saúde. Isso ocorre, pois os fenômenos de iniquidade nos quais iremos nos aprofundar neste artigo dizem respeito à dificuldade, morosidade ou retardamento em obter os desejados cuidados de saúde.

\section{O PRINCÍPIO DA IMPESSOALIDADE}

Partindo do pressuposto, anteriormente levantado, que o Sistema Único de Saúde deve ser considerado como Administração Pública, cumpre-nos elencar os princípios constitucionais que regem esta última.

Destarte, os princípios inerentes à Administração Pública são aqueles expostos no art. 37 de nossa vigente Constituição(7). Alguns, diga-se de pronto, foram positivados de forma expressa. Outros, de forma implícita ou tácita. Trataremos neste artigo, por questão de delimitação de objeto de estudo, apenas dos princípios explícitos, positivados no art. 37:

"Art. 37. Administração Pública direta e indireta de qualquer dos Poderes da União dos Estados, do Distrito Federal e dos Municípios obedecerá aos princípios da legalidade, impessoalidade, moralidade, publicidade e eficiência."

Trataremos adiante de detalhar o segundo dos princípios positivados neste art. 37 da CF/1988: o Princípio da Impessoalidade.

O princípio ou regra da impessoalidade da Administração Pública pode ser definido como aquele que determina que os atos realizados pela Administração Pública, ou por ela delegados, devam ser sempre imputados ao ente ou órgão em nome do qual se realiza, e ainda destinados genericamente à coletividade, sem consideração, para fins de privilegiamento ou da imposição de situações restritivas, das características pessoais daqueles a quem porventura se dirija. Em síntese, os atos e provimentos administrativos são imputáveis não ao funcionário que os pratica, mas ao órgão ou entidade administrativa em nome do qual age o funcionário. Na nomenclatura do campo sanitário, diríamos que os atos e provimentos não seriam imputados aos profissionais, mas à secretaria de saúde, ao hospital etc.

(7) BRASIL. Constituição (1988). 
A mera leitura dessa definição bem nos revela que esse princípio pode ser decomposto em duas perspectivas diferentes: a impessoalidade do administrador (profissional/gestor) quando da prática do ato e a impessoalidade do próprio administrado (usuário) como destinatário desse mesmo ato ${ }^{(8)}$.

Com efeito, de um lado, o princípio da impessoalidade busca assegurar que, diante dos administrados, "as realizações administrativo-governamentais não sejam propriamente do funcionário ou da autoridade, mas exclusivamente da entidade pública que a efetiva" (Silva, 1998, p. 645). Custeada com dinheiro público, a atividade da Administração Pública jamais poderá ser apropriada, para quaisquer fins, por aquele que, em decorrência do exercício funcional, se viu na condição de executá-la. É, por excelência, impessoal, unicamente imputável à estrutura administrativa ou governamental incumbida de sua prática, para todos os fins que se fizerem de direito.

Assim, como exemplos de violação a esse princípio, dentro dessa particular acepção examinada, podemos mencionar a realização de pu-blicidade ou propaganda pessoal do administrador com verbas públicas ${ }^{(9)}$ ou ainda, a edição de atos normativos com o objetivo de conseguir benefícios pessoais.

Já que, por outro ângulo de visão, que será causador dos fenômenos de iniquidade no acesso aos serviços de saúde, mais adiante apresentados, o princípio da impessoalidade deve ter sua ênfase não mais colocada na pessoa do administrador, mas na própria pessoa do administrado (usuário). Passa a afirmar-se como uma garantia de que este não pode e não deve ser favorecido ou prejudicado, no exercício da atividade da Administração Pública, por suas exclusivas condições e características.

Jamais poderá, por conseguinte, um ato do Poder Público, ao menos de modo adequado a esse princípio, vir a beneficiar ou a impor sanção a alguém em decorrência de favoritismos ou de perseguição pessoal. Todo e qualquer administrado deve sempre relacionar-se de forma impessoal com a Administração, ou com quem em seu nome atue, sem que suas características pessoais, sejam elas quais forem, possam ensejar predileções ou discriminações de qualquer natureza.

Será, portanto, tida como manifestadamente violadora desse princípio, nessa dimensão, por exemplo, o favorecimento de parentes e amigos (nepotismo), a tomada de decisões administrativas voltadas à satisfação da agremiação partidária ou facção política a que se liga o administrador (partidarismo), ou

(8) DI PIETRO, Maria Sylvia Zanella, op. cit., p. 65.

(9) É naturalmente dentro dessa perspectiva que se apresenta o $\S 1^{\circ}$ do art. 37 da Constituição Federal, ao determinar que "a publicidade dos atos, programas, obras, serviços e campanhas dos órgãos públicos deverá ter caráter educativo, informativo ou de orientação social, dela não podendo constar nomes, símbolos ou imagens que caracterizem promoção pessoal de autoridades ou servidores públicos". 
ainda de atos restritivos ou sancionatórios que tenham por objetivo a vingança pessoal ou a perseguição política pura e simples (desvio de poder).

Perfilhando este entendimento, sustenta $\mathrm{Mello}^{(10)}$ :

No princípio da impessoalidade se traduz a ideia de que a Administração tem que tratar a todos os administrados sem discriminações, benéficas ou detrimentosas. Nem favoritismo nem perseguições são toleráveis. Simpatias ou animosidades pessoais, políticas ou ideológicas não podem interferir na atuação administrativa e muito menos interesses sectários, de facções ou grupos de qualquer espécie.

\section{O FENÔMENO DA "FILA DUPLA" OU "SEGUNDA PORTA"}

Feitas as devidas considerações preliminares, com o objetivo de aproximar conceitos de áreas de estudos diversos, como já mencionamos na introdução deste trabalho, passamos agora a examinar,de fato o fenômeno da "fila dupla" e, nos deteremos a relacionar o fenômeno em questão, com a inobservância ao Princípio da Impessoalidade por parte dos agentes públicos/ profissionais e gestores do Sistema Único de Saúde.

Até 1990, as pessoas sem capacidade de pagamento ou não contribuintes da previdência social, dependiam da caridade para receber atenção médico-hospitalar. Com a regulamentação do SUS, sistema criado pela Constituição de 1988 e regulamentado pela Lei n. 8.080, de 19 de setembro de 1990, que institucionalizou o acesso universal e igualitário aos serviços de saúde ${ }^{(11)}$, a exclusão formal desapareceu, mas não a iniquidade no acesso aos serviços de saúde no Brasil. Esta subsiste, seja em decorrência de fatores como a desinformação que está associada aos diferenciais de escolaridade, seja por deformação em determinadas políticas públicas. Nessas estão presentes os privilégios e a discriminação.

Além das violações ao Princípio da Impessoalidade que já expusemos, como o nepotismo, e o partidarismo, que se aplicam à administração pública de modo geral, no SUS, vimos acompanhando essa violação pelo fenômeno da "segunda porta" ou "fila dupla" de acesso ao sistema de saúde, no qual hospitais privados e universitários (públicos) atendem pacientes SUS e pacientes privados. Nesse contexto, o que se alega é a tendência a priorizar o atendimento privado em detrimento do paciente financiado pelo sistema público. E havendo duas filas é notório que uma anda mais rápido que a outra.

(10) MELLO, Celso Antônio Bandeira de. Curso de direito administrativo. 7. ed. rev. atual. e ampl. São Paulo: Malheiros, 1995. p. 68.

(11) CARVALHO, G. I.; SANTOS, L. Sistema Único de Saúde: comentários à Lei Orgânica da Saúde (Leis n. 8.080/90 e n. 8.142/90). 3. ed. Campinas: Unicamp, 2001. p.33-53. 
Ao analisar o Projeto n. 449/1999 que pretendia alterar a Lei n. 8.080/1990, Pinotti(12) alerta para as iniquidades geradas pelo fenômeno da "segunda porta":

Legalizada a segunda porta nos hospitais universitários, ela não se restringirá, como não tem se restringido, a diferenças de acomodação. Há esperas, filas e tipos de acolhimento completamente diferenciados; há formas de ocultar o seu volume, muito acima dos 25\%; há ampliações físicas dispendiosas, que contemplam apenas pacientes privados. E, acima disso, há problemas éticos intransponíveis para ensinar os novos médicos, nesse ambiente de acesso e direitos desiguais, no uso privado dos próprios públicos.

No mesmo sentido, temos Salazar et al. ${ }^{(13)}$ :

Outro desvio é a prática ilegal da "fila dupla", quando as unidades do SUS, principalmente hospitais universitários, fazem parcerias com planos de saúde. Nesse caso, os usuários dos planos recebem atenção diferenciada, "furam" a longa fila de espera do SUS para marcar consultas, exames, cirurgias e outros procedimentos, e ainda são atendidos e até internados em melhores acomodações.

Em estudo sobre o Hospital das Clínicas de São Paulo, os autores Conh, Elias e lanni ${ }^{(14)}$ caracterizam o fenômeno como:

(...) ao abrir diferentes portas do hospital para pacientes dos dois sistemas de saúde, implementa um procedimento que não apenas segrega, mas também exclui os usuários do SUS; além disso, ela aponta para o fato de que a "dupla porta" acaba por criar uma dupla fila de espera e de percurso no interior da instituição, portanto segregando e/ou excluindo não apenas do lado de fora, mas também do lado de dentro do hospital. Estes aspectos da discussão sobre a implantação da "dupla porta" têm sido os mais criticados, pois de certa forma apontam para uma diferenciação no atendimento que, segundo os mais críticos, leva à segregação entre os pacientes do sistema público e os do sistema privado, por serem estes beneficiários de privilégios no acesso aos serviços.

Esse tratamento desigual representa ofensa ao princípio constitucional da impessoalidade, que impõe ao Poder Público o dever de não favorecer nem discriminar quem quer que seja por motivos pessoais, como, por exemplo,

(12) PINOTTI, José Aristodemo. Senhores Senadores. Folha de S. Paulo, São Paulo, 16 dez. 2002. Opinião. Disponível em: <http://www1.folha.uol.com.br/fsp/opiniao/fz1612200209.htm>. Acesso em: 15 fev. 2009.

(13) SALAZAR, A. et al. (Orgs.). O SUS pode ser seu melhor plano de saúde. São Paulo: Idec, 2003. p.11.

(14) COHN, A.; ELIAS, P. E.; IANNI, A. M. Z. "Subsídio Cruzado" ou "Dupla Porta": o público e o privado no Hospital das Clínicas de São Paulo. São Paulo: CEDEC, 2002. p. 24-25. (Série Didática, n. 6). 
condição financeira de quem solicita o serviço público. Assim, um estabelecimento de saúde integrante do SUS não pode levar em conta a situação econômica vantajosa do paciente para the conceder atendimento favorecido.

\section{CONSIDERAÇÕES FINAIS}

Apesar da Plenária Final da $12^{\text {a }}$ Conferência Nacional de Saúde, realizada em dezembro, ter aprovado a proibição do atendimento diferenciado a beneficiários de planos de saúde e particulares nas unidades do SUS e hospitais universitários (CNS, 2004), os defensores dessa prática alegam, por exemplo, a autonomia administrativa dos hospitais universitários como razão para manter a prática. Não existe, contudo, argumento que possa rechaçar o fato de que os hospitais universitários são entes da administração pública e, portanto, estão submetidos aos princípios que a regem.

Mediante o exposto, podemos compreender a relação direta entre a violação do Princípio da Impessoalidade por parte do agente público do SUS e a geração de iniquidades no acesso dos usuários aos serviços de saúde. Ao privilegiar um usuário seja por parentesco (nepotismo) ou pelo fato do usuário possuir ou não plano de saúde (fenômeno da dupla porta de entrada no sistema) estará o profissional ou gestor de saúde cometendo ato de improbidade administrativa.

O Estado ou terceiro não poderão prestar qualquer serviço ou ação de saúde, considerando que se trata de uma obrigação do Estado, que não se desenvolva de forma a garantir os princípios que regem a administração pública, mediante a sua estrita observância. O mesmo art. 37, aqui mencionado, quando enumeramos os princípios, agora em seu $\S 4^{\circ}$ passa a considerar a necessidade de punição de determinados atos que venham, justamente, ferir aqueles princípios consagrados em seu caput, determinando sua punição por intermédio da suspensão de direitos políticos, perda da função pública e, quando for o caso, indisponibilidade dos bens e ressarcimento ao erário. A própria Constituição Federal, assim, os qualifica como atos de improbidade administrativa.

Em 1992, o legislador passou a disciplinar a forma de incidência das sanções previstas no referido art. 37. Com efeito, a Lei n. 8.429, de 2 de junho de 1992, denominada Lei de Improbidade Administrativa, passou a prever três categorias de atos de improbidade administrativa: a) os que lesam o erário e enriquecem o agente público de forma ilícita como consequência; b) os que apenas lesam o erário, como resultado da malversação do dinheiro público; c) e os que afrontam - mesmo que não se tenha prejuízo financeiro ao erário a considerar - os princípios que devem ser observados pelos agentes públicos na realização dos atos necessários à Administração. 
Assim, a inobservância ao Princípio da Impessoalidade, estando entre os princípios que devem ser perseguidos pelo administrador, pode levar o administrador da área de saúde a realizar atos de improbidade administrativa.

A fim de que o Princípio da Impessoalidade seja cumprido pelos agentes da administração pública, profissionais e gestores do SUS, e que sua inobservância seja punida como improbidade administrativa na qual se configura, foi que a Constituição Federal legitimou o Ministério Público como forma de garantir o acesso à justiça aos usuários que se sentirem lesados ${ }^{(15)}$.

Porém, se existem disposições legais que legitimam a atuação do Ministério Público nessas questões, o certo é que os Promotores de Justiça e os Procuradores da República têm-se mantido distantes das questões de saúde. É necessário que os membros do Ministério Público assumam uma posição verdadeiramente ativa no que se refere às questões do Sistema Único de Saúde, sobretudo em consideração à natureza relevante - a Constituição define tais ações e serviços como sendo de "relevância pública" dos interesses aí envolvidos.

Assim, é fundamental que o Promotor de Justiça e o Procurador da República se aproximem dos demais agentes, acompanhem de perto o processo de implementação do sistema de saúde e, quando for o caso, utilizem os instrumentos jurídicos existentes para a efetivação concreta dos princípios constitucionais e legais que norteiam o mencionado sistema, já que, só com tal conduta, eles estarão cumprindo com perfeição o seu papel e resguardando a aplicação da universalidade e igualdade do SUS.

\section{REFERÊNCIAS BIBLIOGRÁFICAS}

AITH, Fernando M. A. Curso de direito sanitário São Paulo: Quartier Latin, 2007.

ALMEIDA, Célia. O SUS que queremos: sistema nacional de saúde ou subsetor público para pobres? Ciência e Saúde coletiva [on-line], v. 8, n. 2, p. 346-369, 2003.

ASSIS, M. M. A. et al. Acesso aos serviços de saúde: uma possibilidade a ser construída na prática: Ciência \& Saúde Coletiva, n. 8, v. 3, p. 815-823, 2003.

BOBBIO, Norberto. A era dos direitos. Rio de Janeiro: Campus, 1992.

BRASIL. Constituição (1988).

CARVALHO, G. I.; SANTOS, L. Sistema Único de Saúde: comentários à Lei Orgânica da Saúde (Leis n. 8.080/90 e 8.142/90). 3. ed. Campinas: Unicamp, 2001.

(15) BRASIL, op. cit., arts. 120, inciso II, 127 e 129, inciso II. 
CONFERÊNCIA NACIONAL DE SAÚDE. Brasília. Relatório... Brasília: Ministério da Saúde, 2004.

COHN, A.; ELIAS, P. E.; IANNI, A. M. Z. "Subsídio Cruzado" ou "Dupla Porta": o público e o privado no Hospital das Clínicas de São Paulo. São Paulo: CEDEC, 2002. (Série Didática, n. 6).

DALLARI, Sueli Gandolfi. Direito sanitário. In: ARANHA, Márcio lorio; TOJAL, Sebastião Botto de Barros (Orgs.). Curso de Especialização a distância em Direito Sanitário para Membros do Ministério Público e da Magistratura Federal - Programa de Apoio ao Fortalecimento do Controle Social no SUS. Brasília: UnB, 2002.

DI PIETRO, Maria Sylvia Zanella. Direito administrativo. 6. ed. São Paulo: Atlas, 2003.

O direito administrativo brasileiro sob a influência dos sistemas de base romanística e da common law. Disponível em: <http://www. direitodoestado. com/revista/redae-8-novembro-2006-maria\%20sylvia.pdf>. Acesso em: 20 dez. 2008.

HENRIQUES FILHO, Tarcísio Humberto Parreiras. O Ministério Público e o acompanhamento da gestão do SUS (Sistema Único de Saúde): metodologia para análise e avaliação. Brasília: UnB, 2003.

MEIRELLES, Hely Lopes. Direito administrativo brasileiro. 21. ed. atual. por Eurico de Andrade Azevedo, Délcio Balestero e José Emmanuel Burle Filho. São Paulo: Malheiros 1996.

MELLO, Celso Antônio Bandeira de. Curso de direito administrativo. 7. ed. rev. atual. e ampl. São Paulo: Malheiros, 1995.

MINISTÉRIO DA SAÚDE. Secretaria de Gestão do Trabalho e da Educação na Saúde Departamento de Gestão da Educação na Saúde. Saúde pública e improbidade administrativa (José Marcelo Menezes Vigliar). In: Direito Sanitário e Saúde Pública. Brasília/DF, 2003. (Coletânea de Textos Série E. Legislação de Saúde, v. 1).

MORAES, Eliana Aparecida Silva de. Revista Direito Sanitário, São Paulo, v. 2, n. 1, mar. 2001.

NEGRI, B. A política de saúde no Brasil, nos anos 1990: avanços e limites. In: NEGRI, B.; VIANA, A. (Orgs.). O Sistema Único de Saúde em dez anos de desafio. São Paulo: Sobravine/Cealag, 2002.

PINOTTI, José Aristodemo. Senhores Senadores. Folha de S. Paulo, São Paulo, 16 dez. 2002. Opinião. Disponível em: <http://www1.folha.uol.com.br/ fsp/opiniao/fz1612200209.htm>. Acesso em: 15 fev. 2009.

SALAZAR, A. et al. (Orgs.). O SUS pode ser seu melhor plano de saúde. São Paulo: Idec, 2003. 
SANTOS, Lenir. Saúde: conceito e atribuições do Sistema Único de Saúde. Jus Navigandi, Teresina, ano 9, n. 821, 2 out. 2005. Disponível em: <http:// jus2.uol.com.br/doutrina/texto.asp?id=7378>. Acesso em: 02 maio 2010.

SILVA, José Afonso da. Curso de direito constitucional positivo. 15. ed. São Paulo: Malheiros, 1998.

SILVA, Pâmela Migliorini Claudino da; BERTANI, Íris Fenner. As estratégias de implantação do Sistema Único de Saúde como espaço sócio-político de atuação do assistente social: Semina: Ciências Sociais e Humanas, Londrina, v. 27 , n. 2, p. 107-124, jul./dez. 2006.

TRAVASSOS, Claudia; MARTINS, Mônica. Uma revisão sobre os conceitos de acesso e utilização de serviços de saúde. Caderno de Saúde Pública, Rio de Janeiro, v. 20, supl. 2, 2004. Disponível em: <http://www.scielosp.org/scielo. php?script=sci_arttext\&pid=S0102-311X2004000800014\&lng=pt\&nrm=iso > . Acesso em: 15 fev. 2009.

VIANNA, Solon Magalhães et. al. (coord.). Atenção de alta complexidade no SUS: desigualdades no acesso e no financiamento. Projeto Economia da Saúde, v. 1. Brasília: Ministério da Saúde, IPEA, 2005. Disponível em: <http:// getinternet.ipea.gov.br/economiadasaude/adm/arquivos/destaque/alta complexidade.pdf>. Acesso em: 5 mar. 2009. 